\title{
ARTICLE
}

\section{Mapping rice areas with Sentinel-1 time-series and superpixel segmentation}

\author{
K. Clauss ${ }^{\mathrm{a}}$, M. Ottinger ${ }^{\mathrm{a}}$ and C. Kuenzer ${ }^{\mathrm{b}}$ \\ ${ }^{a}$ Department of Remote Sensing, Institute of Geography and Geology, University of \\ Wuerzburg, Oswald-Kuelpe-Weg 86, D-97074 Wuerzburg, Germany; ${ }^{b}$ German Remote \\ Sensing Data Center (DFD), Earth Observation Center (EOC), German Aerospace Center \\ (DLR), Oberpfaffenhofen, D-82234 Wessling, Germany
}

\section{ARTICLE HISTORY}

Compiled November 6, 2017

\begin{abstract}
Rice is the single most important crop for food security in Asia. Knowledge about the distribution of rice fields is also relevant in the context of green-house relevant methane emissions, disease transmission and water resource management. Copernicus Sentinel-1 provides the first openly available archive of C-band SAR (Synthetic Aperture Radar) data at high spatial and temporal resolution. We developed one of the first methods that shows the potential of this data for accurate and timely mapping of rice growing areas. We used superpixel segmentation to create spatially averaged backscatter time-series, which are robust to speckle and reduce the amount of data to process. This method has been applied to six study sites in different rice growing regions of the world and achieved an average overall accuracy of 0.83 .
\end{abstract}

\section{KEYWORDS}

rice; Sentinel-1; SAR; time-series; image segmentation; agriculture

\section{Introduction}

Rice agriculture plays a significant role in the context of climate change, water resource management and, most importantly, food security. Rice is the staple food for a majority of the world's population, especially in developing regions in Asia, Latin America and Africa (Kuenzer and Knauer 2013; Dobermann and Fairhurst 2000; Alexandratos and Bruinsma 2012). The global population is constantly growing and expected to surpass the 8 billion threshold by 2040 (United Nations 2015). This leads to a growing demand in rice, wheat and other cereals that make up a large portion of the caloric intake for a majority of the global population (Alexandratos and Bruinsma 2012). While the demand for rice is growing, our ability to forecast rice production is still limited and dominated by costly and labour intensive surveys and error prone extrapolation methods. At the same time climate change is leading to an increase in weather extremes such as droughts and floods (Field et al. 2012), which can destroy rice crops and impact the food security and farmers livelihoods at local and regional scales. A key to understanding how much rice is produced at any given time are accurate and timely maps of paddy rice area. Satellite based remote sensing can aid the production of such 
maps for large areas in a timely and reproducible manner (Xiao et al. 2006; Bouvet and Le Toan 2011). Paddy rice fields are periodically flooded and, as a result, paddy rice agriculture consumes up to one third of the globally available freshwater (Bouman 2009). Globally there is an estimated 129 million hectares (Mha) of paddy cropland of which 66 Mha is irrigated and 63 Mha rainfed (Salmon et al. 2015). The temporarily flooded fields are a man-made wetland and habitat for mosquitoes, waterfowl and other water organisms impacting biodiversity and disease transmission (Richards et al. 2010; Donald 2004; Longoni 2010). Anaerobic conditions in the flooded soil lead to significant $\mathrm{CH}_{4}$ (methane) emissions and make paddy rice ecosystems one of the main contributors of this green-house relevant gas (Keppler et al. 2006). Understanding the when and where of rice is therefore important in the context of, but not limited to, food security, water resource planning, run-off water management, disease and pest control and climate modelling.

Rice is the only cereal that is commonly grown under flooded conditions and requires an abundance of water during the initial growing stages. Rice can be transplanted or directly seeded into flooded or wet soils and the subsequent growth of the plants can be divided into 10 growing stages which are grouped into three growing phases (De Datta 1981). First is the vegetative phase consisting of the germination, seedling, tillering and stem elongation stages. The reproductive phase consists of the stages panicle initiation, heading and flowering. Finally, the ripening phase includes the milk, dough and mature grain stages. Each change in stage is linked to a change in plant morphology. These changes in plant morphology also affect how the rice plants interact with waves that are detected by active or passive remote sensing sensors. This unique temporal variability of wave-plant-water interactions can be exploited to map rice growing areas with spaceborne multispectral and SAR sensors. This feature is especially visible in the analysis of time-series of remotely sensed data, where the analysis of the temporal signal enables the distinction between rice and other land cover classes, especially other commodity crops. Multiple reviews on the remote sensing of rice showed that the analysis of timeseries has been the most prolific technique for rice mapping (Kuenzer and Knauer 2013; Mosleh, Hassan, and Chowdhury 2015; Dong and Xiao 2016).

In the domain of microwave remote sensing two major methodologies for rice mapping have evolved. One uses radar polarimetry and sensor with the ability to acquire images at multiple polarisations to differentiate rice crops from other land cover or detect rice growing stages, exploiting the fact that the structure of rice plants attenuates vertically polarised waves more than horizontally polarised waves (Ribbes 1999; Le Toan et al. 1997; Lopez-Sanchez et al. 2014). This study can be grouped into the second category, which exploits the temporal variation in received backscatter from rice fields for their detection. The temporal signal of SAR backscatter can be regarded as a function of rice crop growth. In the early stages the rice seedlings are completely submerged in the water of the flooded fields. During this stage the specular reflection (figure $1-a)$ on the water surface is the dominant backscatter mechanism resulting in very little backscatter. As the plant emerges through the water surface the mechanisms of double bounce and multiple bounces (figure $1-b, c$ ) cause an increase in backscatter. The backscatter increases with the rice plants vertical growth until it reaches the heading stage. In the later growth stages the mechanism of volume scattering (figure $1-\mathrm{d}$ ) dominates and the backscatter decreases. This temporal behaviour has been observed at the Ka-, Ku-, X-, C- and L-band wavelengths and was, for Cband, theoretically explained by backscatter models from Monte Carlo simulations (Le Toan et al. 1997; Wang et al. 2005; Inoue et al. 2002). Rice areas have been mapped with data from C-, L- and X-band sensors, with the majority of the studies using data 
(a)

(b)

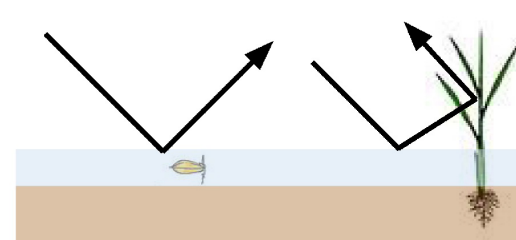

(c)
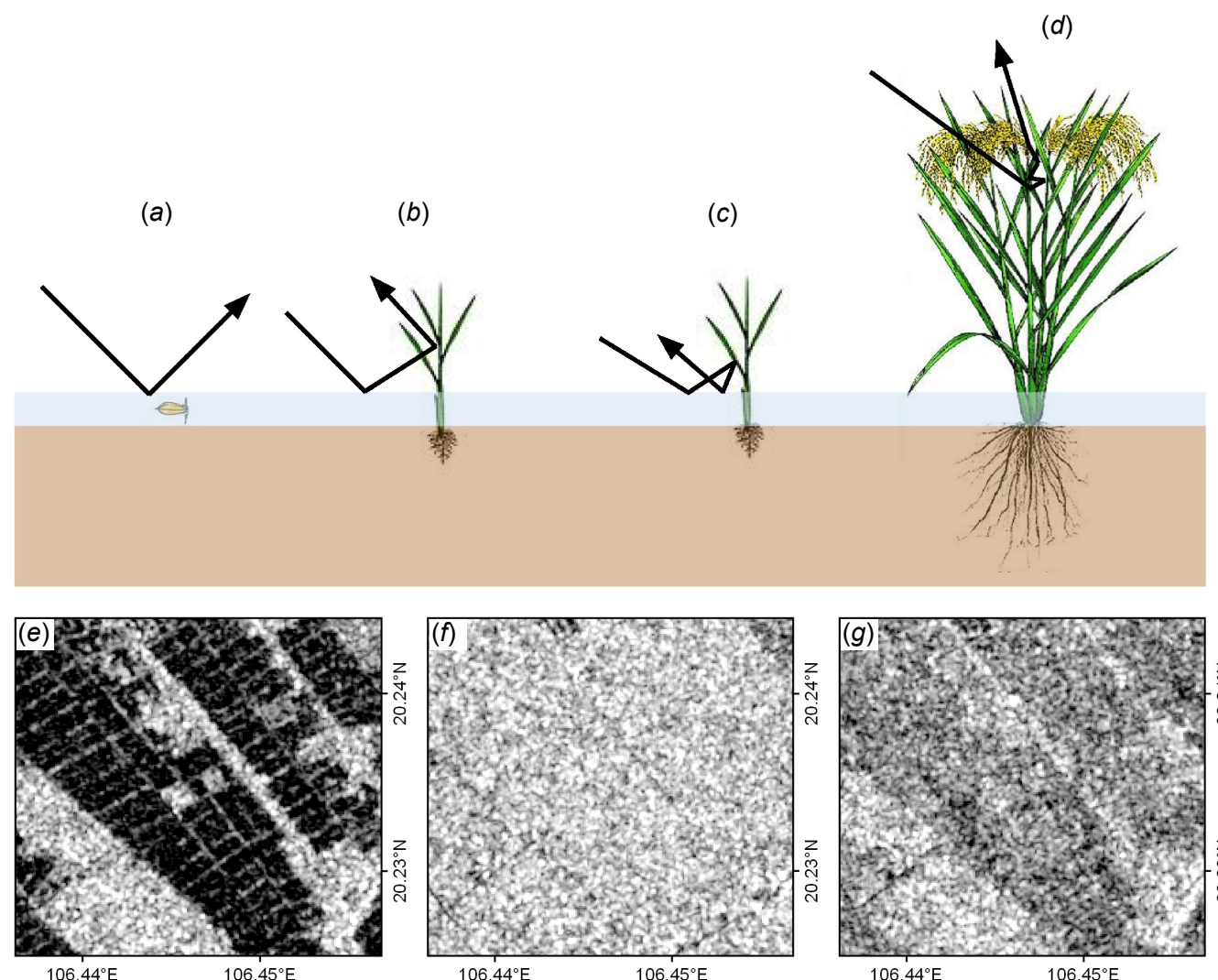

$\Delta$\begin{tabular}{cccc}
0 & 500 & 1000 & $1500 \mathrm{~m}$ \\
\hline & $\perp$ & $\perp$ & -1
\end{tabular}
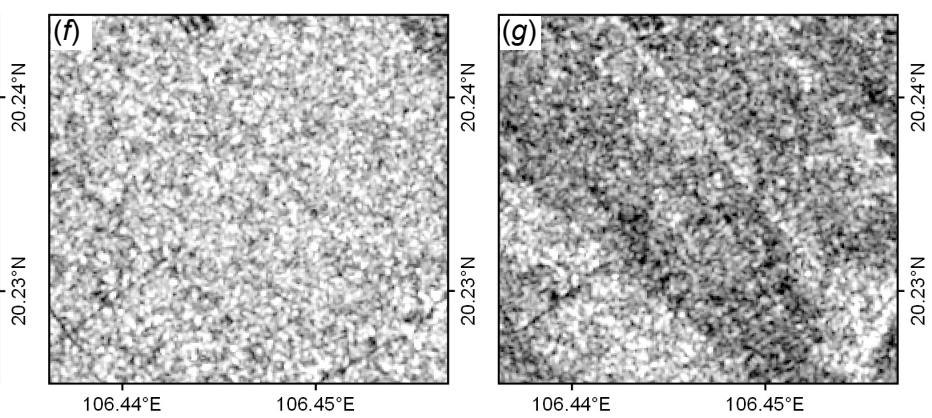

$106.45^{\circ} \mathrm{E}$

Figure 1. Backscatter mechanisms in dependence of rice crop growth $(\mathrm{a}-\mathrm{d})$. Sentinel-1 images of rice fields near Giao Thuy during the flooding (e), heading (f) and mature grain stages (g). 
acquired at the C-band.

Time-series of spaceborne SAR sensors have been used to map rice growing regions since 1991 with the availability of data from the European Remote Sensing Satellite 1 (ERS-1) in Canada (McNairn and Brisco 2004; Jia et al. 2013), India (Patel et al. 1995; Chakraborty, Panigrahy, and Sharma 1997; Panigrahy et al. 1997; Premalatha and Nageswara Rao 1994), Indonesia (Le Toan et al. 1997), Japan (Le Toan et al. 1997; Kurosu, Fujita, and Chiba 1995, 1997), Thailand (Aschbacher et al. 1995) and Vietnam (Liew et al. 1998a). These initial studies laid important ground work in regards to method development, which was successfully transferred to succeeding SAR sensors. Radarsat-1 had a shorter repeat cycle and has been used to map rice areas with horizontal co-polarised time-series in India (Choudhury and Chakraborty 2006; Chakraborty et al. 2005; Panigrahy et al. 1999), Indonesia (Ribbes 1999), China (Li et al. 2003; Shao et al. 2001; Wu et al. 2011; Zhang et al. 2016) and Japan (Yonezawa et al. 2012) as well as the first multi-sensor studies in conjunction with ERS-1/2 data (Liew et al. 1998a). Envisat ASARs (Advanced Synthetic Aperture Radar) WideSwath mode enabled rice mapping at regional scales (Bouvet and Le Toan 2011; Bouvet, Le Toan, and Lam-Dao 2009; Nguyen et al. 2015) and X-band sensors TerraSAR$\mathrm{X}$ and COSMO-SkyMed (Constellation of Small Satellites for Mediterranean basin Observation) enabled paddy rice mapping at unprecedented spatial resolution (LopezSanchez, Ballester-Berman, and Hajnsek 2011; Koppe et al. 2013; Nguyen et al. 2012; Nelson et al. 2014). These studies employed SAR time-series for mapping rice areas, have focused on rice grown under flooded conditions, and report accuracies ranging from $81 \%$ to $98 \%$.

Most studies employing the time-series backscatter change method highlight the SAR sensors capabilities to acquire images unaffected by frequent cloud cover and availability of daylight, distinguishing them from methods developed for multi-spectral optical sensors. However, most studies also mention, that the largest limiting factor for this method is a lack of available data. In contrast to the open archives of multi-spectral data from sensors such as MODIS (Moderate Resolution Imaging Spectroradiometer) and the Landsat missions there has been no open archive of SAR data. Classifying rice areas requires temporally dense time-series, for which the acquisition is costly and archives often have limited temporal and spatial coverage. This changed with the launch of the first satellite of the Copernicus programme - Sentinel-1A. It is the first SAR C-band mission that has the goals of global coverage, continuity, temporally dense coverage and free and open data access built-in from the start. Today the archive of Sentinel-1A/B data grows at a rate of 10 Terabytes a day. This study is one of the first seeking to exploit this archive in regards to remote sensing of rice growing regions. We aim to show that time-series of Sentinel-1 data can be used to map rice in a variety of regions, paving the way forward for globally consistent, high resolution rice maps.

The goal of this study is to evaluate the performance of a paddy rice classification method that is: 1) able to analyse dense Sentinel-1 C-band SAR time-series and 2) can be spatially transferred to different rice growing regions in order to help in the timely mapping and monitoring of paddy rice areas with Sentinel-1 data.

\section{Study Sites and Data}

Rice is grown in climates ranging from tropical to temperate regions, between $50^{\circ}$ north and $40^{\circ}$ south and at elevations up to $2600 \mathrm{~m}$ (De Datta 1981). To reflect this diversity, we developed our method on six study sites scattered around the globe (see 


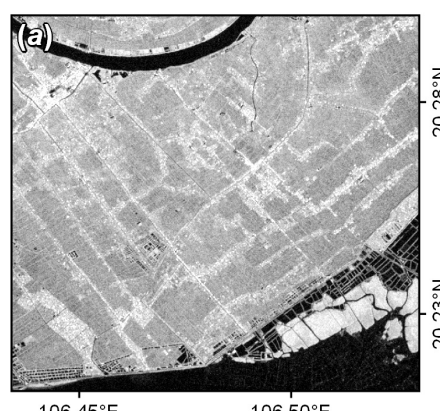

106. $45^{\circ} \mathrm{E}$

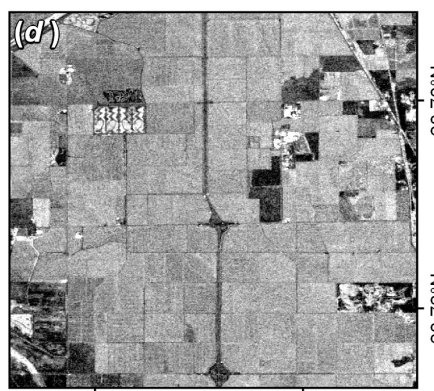

$121.57^{\circ} \mathrm{W}$
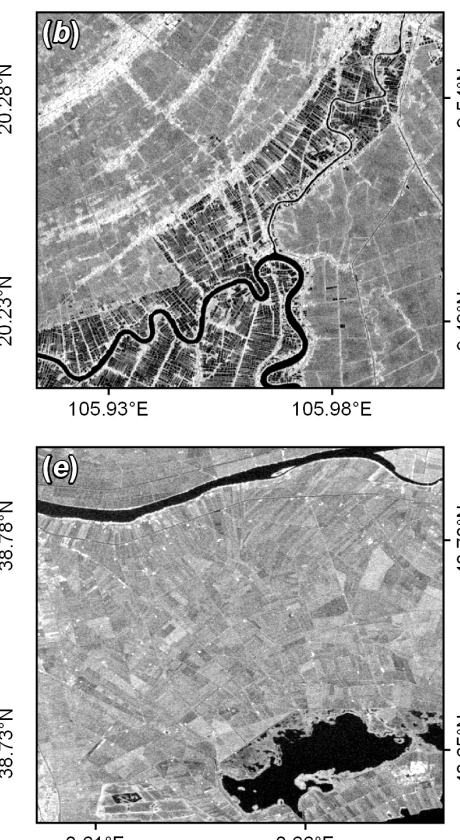

$0.66^{\circ} \mathrm{E}$
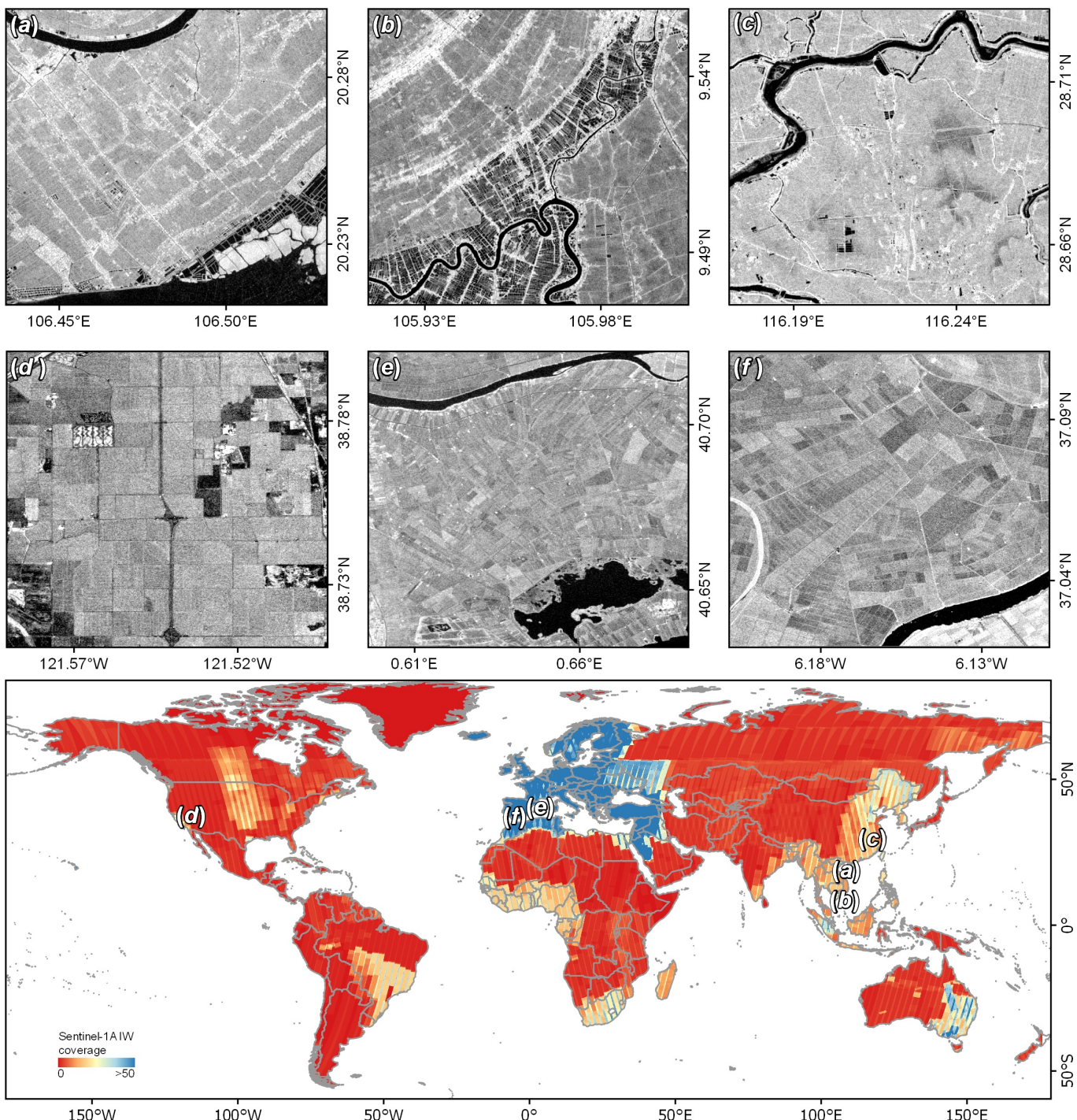

Figure 2. Study site locations and Sentinel-1A coverage 2015. (a) - Giao Thuy, Red River Delta, Vietnam. (b) - Soc Trang, Mekong Delta, Vietnam. (c) - Poyang Lake, China. (d) - California, USA. (e) - Ebro Delta, Spain. (f) - Isla Mayor, Spain. 
figure 2). In Asia, these study sites are located at the Poyang Lake in China, the Red River Delta in northern Vietnam and the Mekong Delta in southern Vietnam. These areas are characteristic for rice growing regions in Asia with comparatively small field sizes, irregular field shapes, a moderate amount of mechanization, diverse cropping calendars and often the growth of multiple (rice)-crops per field and year. According to Köppen-Geiger the climate zones in these study sites range from Monsoon (Am) in Soc Trang to humid subtropical (Cwa) in Giao Thuy and warm oceanic (Cfa) at Poyang Lake (Peel, Finlayson, and McMahon 2007). The variety in climate is also visible in the climate charts for 2015 (see figure 3) where Soc Trang has monthly mean minimum temperatures exceeding $20^{\circ} \mathrm{C}$ and enabling rice growth throughout the whole year with up to three rice seasons. The first season is planted October or November of the previous year and lasts until February to May. It is followed by the Summer-Autumn season from around March to August and finally the Winter season from August to November. Favourable climate conditions allow for diverse shifts in the exact transplanting and harvest dates depending on farmer's choice resulting heterogenous crop calendars within our study site. In Giao Thuy up to two rice seasons are cultivated in the Spring or Early Rice season from February to July followed by the Summer or Late Rice season from July to September. In our study site, as well as large parts of the Red River Delta, these are followed by a season for winter crops, mainly vegetables such as cabbage, leek, onions, lettuce or cucumber, lasting from October to February. The Poyang Lake region has a temperature profile with a higher amplitude and lower winter temperatures than both Vietnam study sites enabling up to two rice crops in a year. The first season, Early rice, is transplanted around March, harvested end of July and immediately followed by the Late rice season which is harvested in November. Due to little time between the two seasons the process is locally referred to as rush-harvesting and rush-transplanting (Li et al. 2012). The main planting technique throughout these three study sites is transplanting of rice seedlings from seedbeds into the paddy fields.

In Europe, we selected two study sites in Spain - in the Delta of the Ebro River in eastern Spain and the Isla Mayor region in south-west Spain. Both study sites have less precipitation than the ones located in Asia but no shortage of irrigation water due the location close to major rivers, a higher degree of mechanization and grow longer duration rice varieties. Their climate zone is warm Mediterranean (Csa) (Peel, Finlayson, and McMahon 2007). The temperature profile throughout 2015 is similar to the Poyang Lake region, albeit with higher temperatures from November to February, and in both a single rice crop is cultivated per year starting around May and lasting up to October or November. In contrast to the study sites in Vietnam and China a rice variety with a longer growing cycle is transplanted. The sixth focus region is located near Sacramento, USA, in the rice growing region of California. Rice is grown on large farms, on clay soils and with a high degree of mechanization. Rice is an important crop in California despite an ongoing drought, associated water shortage and water rationing for agricultural areas. California had the lowest amount of precipitation in 2015 from all our study sites and is located in the warm Mediterranean climate zone (Csa) (Peel, Finlayson, and McMahon 2007). One rice crop with a long growing cycle duration is grown from May to August. In contrast to the study sites in Asia, direct seeding over the transplanting technique is employed in California and Spain. Rice seeds are soaked in water and brought out into the furrowed and flooded fields by planes or tractors. Due to the drought, not all paddy fields in California are cultivated in 2015, depending on water availability. All study sites feature paddy fields where the water level is managed through irrigation from channels or wells. To enhance the 

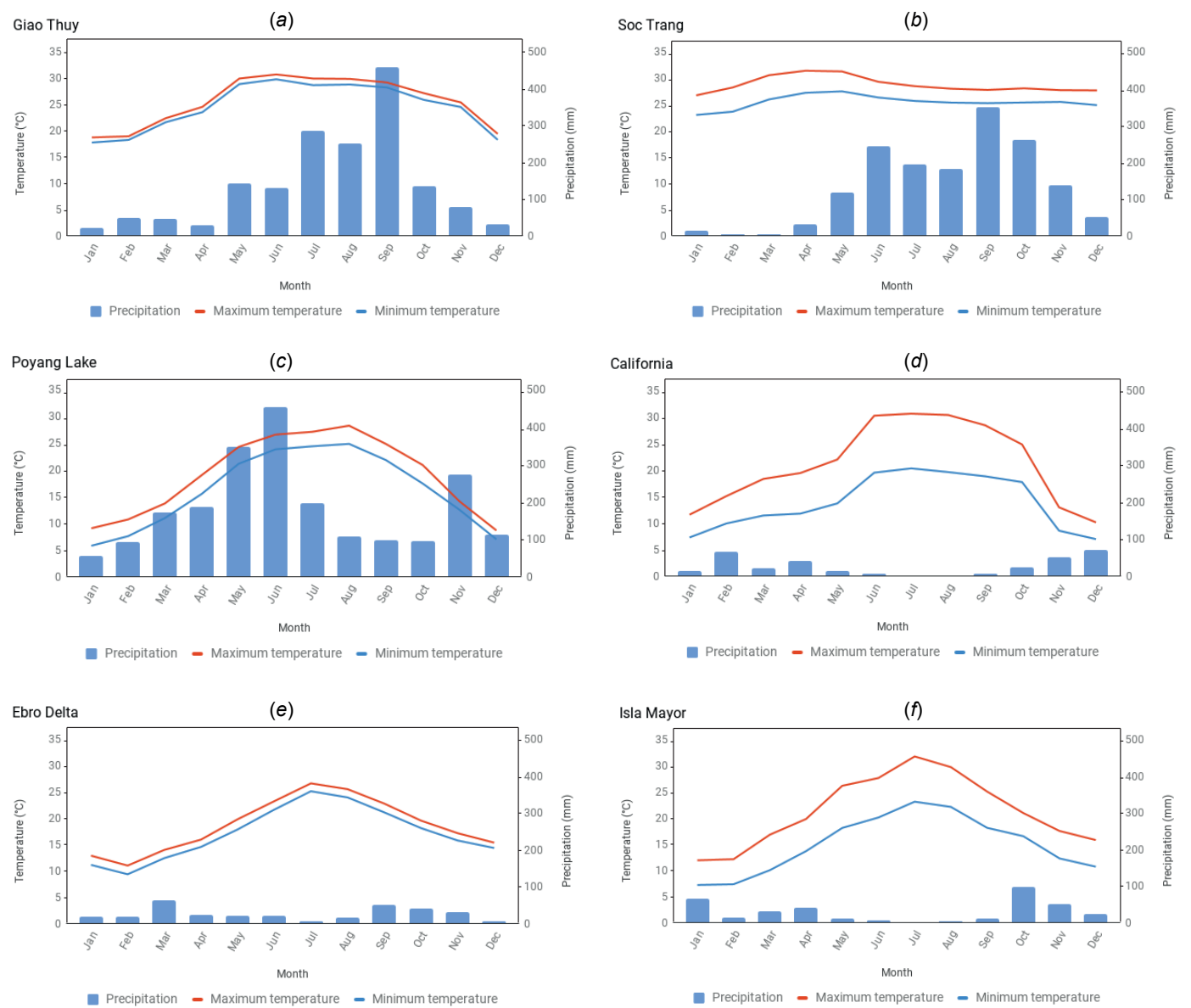

Figure 3. Climate charts for 2015 for the study sites. Monthly mean temperatures are aggregated from the Climate Forecast System (NCEP CFSv2) (Saha et al. 2014). Monthly precipitation data is summed from the Climate Hazards Group InfraRed Precipitation with Station data (CHIRPS) (Funk et al. 2015)

comparability of our results all study sites are defined by a $10 \mathrm{~km} \times 10 \mathrm{~km}$ rectangle.

We used time-series of images acquired by the Sentinel-1A Synthetic Aperture Radar sensor at C-band. The Sentinel-1A satellite was launched on 3 April 2014 and the regular publication of datasets started after the In-Orbit Commission Review on 3 October 2014. The revisit time of this polar-orbiting satellite is 12 days at the equator. The SAR sensor aboard the satellite is right looking and acquires images at C-band with a centre frequency of $5.405 \mathrm{GHz}$. Incidence angles can range from $20^{\circ}$ to $47^{\circ}$, radiometric accuracy is within $1 \mathrm{~dB}$ and the Noise Equivalent Sigma Zero (NESZ) is $-22 \mathrm{~dB}$. Available polarisations in the default operation mode over land are vertically transmitted and received (VV) and vertically transmitted horizontally received (VH) in Interferometric Wide Swath (IW) acquisition mode with a swath width of $250 \mathrm{~km}$. The geometric resolution is $5 \mathrm{~m} \times 20 \mathrm{~m}$ Incidence angles for the IW acquisition mode range from $29^{\circ}$ to $46^{\circ}$. Datasets are delivered as L1C products in Single-Look Complex (SLC) format or as multi-looked intensity images in Ground Range Detected (GRD) format with a pixel spacing of $10 \mathrm{~m}$ (Sentinel-1 Team 2013). On 25 April 2016 Sentinel$1 \mathrm{~B}$ was launched, which is functionally identical to Sentinel-1A, uses the same orbit plane and effectively halves the revisit time and doubles the amount of acquisitions allowing for the creation of SAR time-series with an unprecedented temporal density 
at this resolution.

As the source for our rice classifications we used all Sentinel-1 Interferometric Wide Swath (IW) data in Ground Range Detected High Resolution (GRDH) format and dual polarisation available for each study site and the complete year 2015. Sentinel-1 data in the IW acquisition mode and GRDH format was acquired from the Copernicus Open Access Hub (https://scihub.copernicus.eu). Product names for all 137 Sentinel1 scenes used in this study are given in the supplement S1. To minimize the effects of orbit direction and look angle we only used scenes from an ascending orbit for the study sites in China and USA and descending orbit for study sites in Spain and Vietnam.

\section{Methodology}

\subsection{Rice classification with Sentinel-1 time-series}

The data was pre-processed to generate the backscatter coefficient $\sigma^{0}$, also known as sigma0 or sigma nought, using pre-processing steps implemented in the Sentinel Application Platforms (SNAP) Sentinel-1 Toolbox software. First, an orbit file was applied using restituted orbits and thermal noise present at the range direction scene edges was removed. After radiometric calibration orthorectification was performed to remove terrain effects using the Shuttle Radar Topography Mission (SRTM) Digital Elevation Model (DEM) with 1 arc second resolution. These pre-processing steps have been performed by the Google Earth Engine (https://earthengine.google.com/) team prior to ingesting the scenes into an analysis ready data cube (figure $4-1$ ). For each study site we selected scenes from this data cube, which have been recorded in the year 2015.

For our study sites in China and the USA more scenes are available in ascending orbit and for the study sites in Spain and Vietnam we selected scenes from descending orbits. This results in six subsets of the Sentinel-1 data cube - one for each study site.

We calculated three temporal metrics for each study site. Multi-temporal metrics are a well-established method used for land cover classification and are able to capture temporal patterns even in irregular spaced time-series (Hansen et al. 2014; Müller et al. 2015). For the VH polarisation we calculated the 50th percentile and the standard deviation of $\sigma^{0}$ for the year 2015. Additionally, the 10th percentile of the VV polarised data was calculated. These temporal metrics were chosen as they create a well-defined contrast of land cover with high $\sigma^{0}$ time-series amplitudes, such as agriculture, compared to land cover with lower time-series amplitudes, such as water and built-up. The temporal evolution of $\sigma^{0}$ time-series for five exemplary land cover classes is given in figure 5, which shows that the use of metrics such as the median and 10th percentile are able to distinguish rice and other agricultural areas from land cover with high backscatter, i.e. mangrove and built-up and from land cover with constant low backscatter, i.e. rivers and aquaculture. The resulting three band images are used as input for our segmentation procedure and have been exported out of the Earth Engine platform in GeoTiff format, with the original coordinate reference system at a pixel resolution of $10 \mathrm{~m}$.

We then performed image segmentation using the simple linear iterative clustering (SLIC) superpixel algorithm (Achanta et al. 2012) implemented in the scikit-image Python package in version 0.12 (van der Walt et al. 2014). SLIC was selected due to its speed and ability to perform well in all study sites with a single set of parameters. 


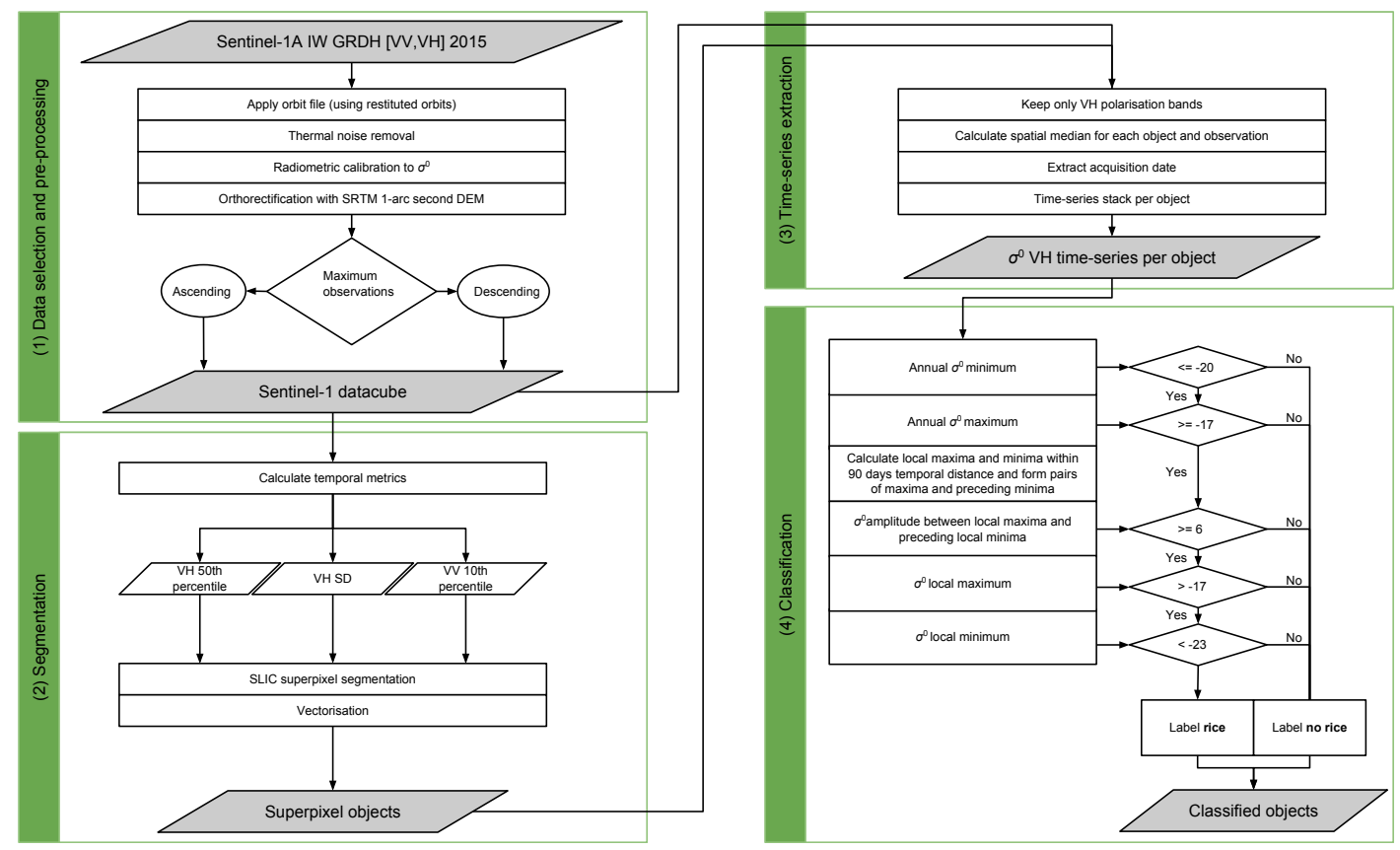

Figure 4. Rice classification based on Sentinel-1 time-series.
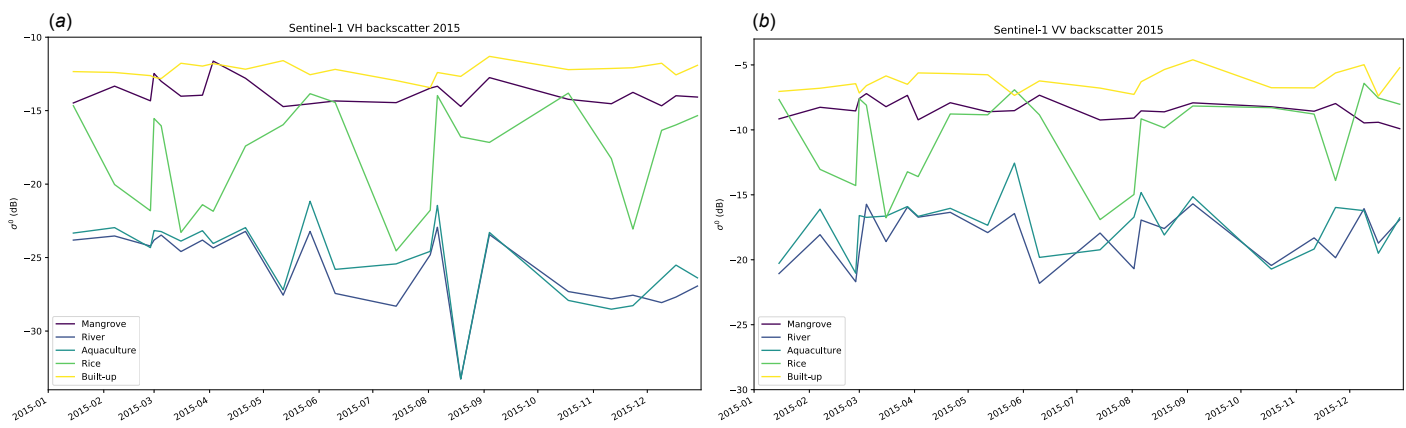

Figure 5. Temporal evolution of Sentinel-1 backscatter at VH (a) and VV polarisation (b) for five land cover classes in Giao Thuy. 
Our aim was to create a method that would work well in different rice growing regions without the need for empirical parameter selection in each study area, which was why we chose to use a superpixel algorithm. SLIC is one of the fastest superpixel algorithms while also requiring a minimum amount of parameters to select and 'groups pixels into perceptually meaningful atomic regions' (Achanta et al. 2012). While SLIC is a very robust segmentation algorithm, the selection of the number of segments it should create per study site as well as the compactness of each segment still has a discernible influence on the resulting segments. We selected the values empirically based on local knowledge of the study areas. Since our study areas represent a wide array of different climates, crop calendar, farming strategies and field sizes, we assume that these parameters should be applicable to most rice growing regions of the world. For segmentation parameters we selected values of 2500 for the number of segments (n_segments) and 75 for compactness, which balances colour and space proximity of the segments. Image segmentation was performed with identical parameters on all study sites. The resulting raster images with labelled segments have been ingested back into the Earth Engine platform. There we performed a vectorization procedure resulting in a multi-polygon vector dataset with uniquely labelled polygons for each superpixel object (figure 4 - 2).

These superpixel polygons were then used in conjunction with the Sentinel-1 data cube subsets to extract $\sigma^{0}$ time-series. We limited the data cube to $\mathrm{VH}$ polarised data. We chose VH over VV polarisation due to the higher dynamic range of backscatter over rice areas caused by agronomic flooding followed by vertical plant growth. For each polygon, we then calculated the spatial median of $\sigma^{0}$ values and the acquisition date, given in the metadata as 'beginposition', for each Sentinel-1 scene. Scene boundaries of Sentinel-1 GRD scenes for a single orbit path can differ significantly in azimuth direction and are not rectangular due to the TOPSAR (Terrain Observation with Progressive Scans SAR) scanning technique (Sentinel-1 Team 2013). If one of those scene boundaries intersects a polygon it is only partially filled with valid measurements and data for this polygon-scene combination was discarded.

This results in a spatially averaged $\sigma^{0}$ time-series at $\mathrm{VH}$ polarisation for each superpixel object (figure 6). These time-series have been exported out of the Earth Engine platform in comma separated value (CSV) format for further analysis (figure 4 - 3).

Classification of the time-series was performed with a simple, phenology based decision tree with five decision nodes. Classification of the time-series is the final step in our processing system (figure 3 - 4). We used a phenology based decision tree and the extracted time-series to classify each object as either rice or no rice. Decision trees are commonly used for classification of rice areas from remotely sensed time-series of multispectral (Xiao et al. 2006; Wang et al. 2015; Shi and Huang 2015; Dong et al. 2016; Clauss, Yan, and Kuenzer 2016) and SAR data (Liew et al. 1998b; Choudhury and Chakraborty 2006; Torbick et al. 2011a; Nguyen et al. 2015; Nelson et al. 2014) or a combination of both (Torbick et al. 2011b, 2017). We chose this classification method due to its proven performance and replicability and wanted to test its regional transferability and performance using Sentinel-1 time-series. A phenology based decision tree requires no training data, is not computationally intensive and thus enables scaling and transferability to other rice growing regions. Our choice of decision criteria was guided by previous studies in the Mekong Delta as well as input from local experts (Bouvet, Le Toan, and Lam-Dao 2009; Nguyen et al. 2015). The thresholds have not been adapted to the other study regions, as we aimed to devise a method that could be regionally transferred without the need for study site specific training data. Our decision tree consists of five decision nodes. The first features we considered 

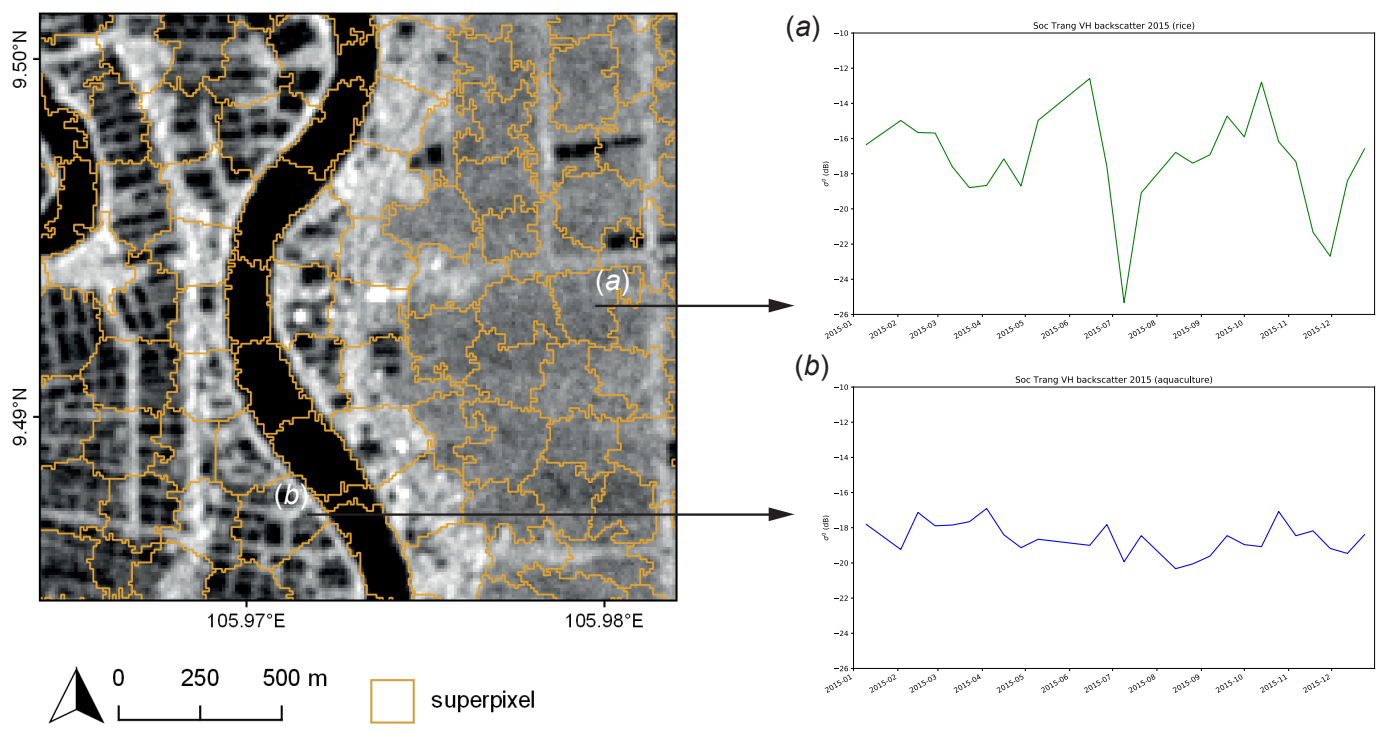

(b)

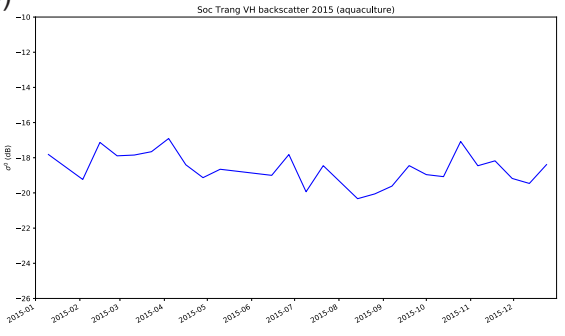

Figure 6. Spatially averaged superpixel time-series in Soc Trang over rice (a) and aquaculture (b) areas.

for classification were annual maxima and minima of the measured backscatter. The temporal $\sigma^{0}$ signal of rice fields has very distinct minima when the paddy fields are flooded and maxima at the heading stage of the rice plants. From previous studies we know that these first two decision nodes are valid to differentiate seasonal vegetation, such as crops and deciduous forests, from land cover with a constantly low backscatter, such as water bodies, or high backscatter, such as urban areas (Zhu et al. 2012; Kuenzer et al. 2013; Shimada et al. 2014; Nguyen et al. 2015; Clauss, Yan, and Kuenzer 2016). If the annual minimum of the $\sigma^{0}$ time-series was larger than $-20 \mathrm{~dB}$ or the annual maximum was smaller than $-17 \mathrm{~dB}$ the object was classified as no rice. The flooding and heading stages of rice plants can be detected as local minima and maxima in backscatter time-series. We calculated the local extrema of our time-series within 90 day windows. The temporal distance was chosen based on the shortest possible growing season for rice plants within the regions of our study sites. Local minima and their following local maxima were grouped into pairs for further calculation. This is necessary due to the effects of multi-cropping, the practice of farmers planting multiple crops within a year on the same field, which also results in multiple peaks and troughs in our observed backscatter time-series. For each pair we regarded the backscatter difference between a local maximum and the preceding local minimum. The difference between the local extrema has to exceed $6 \mathrm{~dB}$ to be considered as a rice area. The final classification criterion is fulfilled if either the local minimum is smaller than $-23 \mathrm{~dB}$ or the local maximum exceeds $-17 \mathrm{~dB}$. If these three decision tree nodes were fulfilled by any extrema pair within the time-series, the object was classified as rice, since at least one crop during the year can be considered rice.

\subsection{Accuracy Assessment}

We performed our accuracy assessment based on stratified random sampling and classification by remote sensing and local experts. Each study site was stratified into two classes according to our classification result and 100 points have been randomly sam- 
Table 1. Very high resolution satellite images used as reference data.

\begin{tabular}{llll}
\hline Study site & Acquisition date & Sensor & Source \\
\hline Giao Thuy & 30 May 2015 & SPOT-6 & DeltAdapt project \\
Soc Trang & 2 February 2015 & SPOT-6 & DeltAdapt project \\
Poyang Lake & 12 July 2015 & & Google Earth (Airbus) \\
California & 16 December 2015 & RapidEye & Planet Open California archive \\
Ebro Delta & 31 March 2015 & & Google Earth \\
Isla Mayor & 15 May 2015 & & Google Earth \\
\hline
\end{tabular}

pled for each of the classes rice and no rice. Using 100 samples per class is twice the recommend sample size for study areas less than 1 million acres in size (Congalton and Green 2009). The resulting dataset of 1200 points was then manually classified by two remote sensing specialists. For points of disagreement in the Vietnam and China regions we gathered input from local experts for the labels. Points of disagreement in the remaining regions were labelled by a third remote sensing specialist and classified according to majority vote. As reference data we selected very high resolution (VHR) satellite images acquired in 2015 available to us via the DeltAdapt project, the Planet Open California archive and Google Earth (see table 1).

In a first step, all points were tested for no rice based on their location. Every point visibly located outside a field or agricultural area and at land cover belonging to the no rice class, such as built-up, water and forest, was classified as no rice. The remaining points belonged to the class agriculture and needed further reference data to determine whether they are located at rice fields or other crops.

For all remaining points we selected valid Landsat-8 observations in 2015 at pixel level, calculated the indexes LSWI (Land Surface Water Index) and EVI (Enhanced Vegetation Index) and plotted the resulting time-series. Those time-series plots were then manually inspected for visible inversions followed by a rapid EVI increase, which indicates rice growth (Dong et al. 2016; Xiao et al. 2002, 2006; Clauss, Yan, and Kuenzer 2016). If a point was located within a field and fulfilled this inversion criterion it was labelled as rice. However, if no inversion was visible it was labelled as no rice.

The resulting dataset has 1200 points with two labels each, the class based on our Sentinel-1 time-series methodology and the class from the manual interpretation of VHR imagery and Landsat- 8 time-series. For calculation of accuracy metrics the latter was regarded as ground truth. For each study site we calculated the overall accuracy as the number of correctly classified points divided by the total number of points. The producer's accuracy was calculated for each class as the fraction of correctly classified points regarding all ground truth points of that class, whereas the user's accuracy was calculated as the fraction of correctly classified points regarding all points classified as this class.

\section{Results}

We mapped paddy rice areas with overall accuracies ranging from 0.78 in California to 0.87 in Giao Thuy and the Ebro Delta (table 2). The user's accuracy for our target class rice is always greater or equal 0.82 in six different study sites. For the rice class the lowest producer's and user's accuracy was achieved in California, whereas the highest producer's accuracy was accomplished in the Ebro Delta and the highest user's accuracy at the Isla Mayor study site. For the no rice class producer's accuracy was lowest in the Ebro Delta and highest in Soc Trang and Isla Mayor, while the user's 
Table 2. Accuracy assessment per study site - Overall Accuracy (OA), Producer's Accuracy (PA) and User's Accuracy (UA) given for the classes rice $(r)$ and no rice $(\mathrm{nr})$.

\begin{tabular}{lccccc}
\hline Study site & OA & PA $_{\mathrm{r}}$ & $\mathrm{PA}_{\mathrm{nr}}$ & $\mathrm{UA}_{\mathrm{r}}$ & $\mathrm{UA}_{\mathrm{nr}}$ \\
\hline Giao Thuy & 0.87 & 0.88 & 0.85 & 0.85 & 0.88 \\
Soc Trang & 0.85 & 0.82 & 0.88 & 0.89 & 0.81 \\
Poyang Lake & 0.81 & 0.78 & 0.85 & 0.87 & 0.75 \\
California & 0.78 & 0.73 & 0.86 & 0.89 & 0.67 \\
Ebro Delta & 0.87 & 0.90 & 0.83 & 0.82 & 0.91 \\
Isla Mayor & 0.82 & 0.78 & 0.88 & 0.90 & 0.74 \\
\hline
\end{tabular}

accuracy was highest in the Ebro Delta and lowest in California.

The accuracy assessment was performed for each study site individually. For Giao Thuy 85 of 100 points and 88 of 100 points have been correctly classified as rice and no rice respectively. In Soc Trang 89 of 100 rice and 81 of 100 no rice points have been correctly classified. In the study site at the Poyang Lake 87 of 100 and 75 of 100 points have been correctly classified as rice and no rice, respectively. In California we achieved 89 of 100 correctly classified rice and 67 of 100 no rice points. For the study sites in Spain we correctly classified 82 of 100 rice points in the Ebro Delta and 90 of 100 at Isla Mayor. In the 91 of 100 and 74 of 100 no rice points have been correctly classified in the Ebro Delta and Isla Mayor, respectively.

Maps of paddy rice areas in six study sites based on Sentinel-1A time-series from 2015 are shown in figure 7 . The area of paddy rice for each study site can be given as $38.13 \mathrm{~km}^{2}$ for Giao Thuy (figure 7 - a), $33.65 \mathrm{~km}^{2}$ for Soc Trang (figure 7 - b), 47.34 $\mathrm{km}^{2}$ for Poyang Lake (figure 7 - c), $28.45 \mathrm{~km}^{2}$ for California (figure 7 - d), $66.11 \mathrm{~km}^{2}$ for Ebro Delta (figure 7 - e) and $80.20 \mathrm{~km}^{2}$ for Isla Mayor (figure 7 - f). 


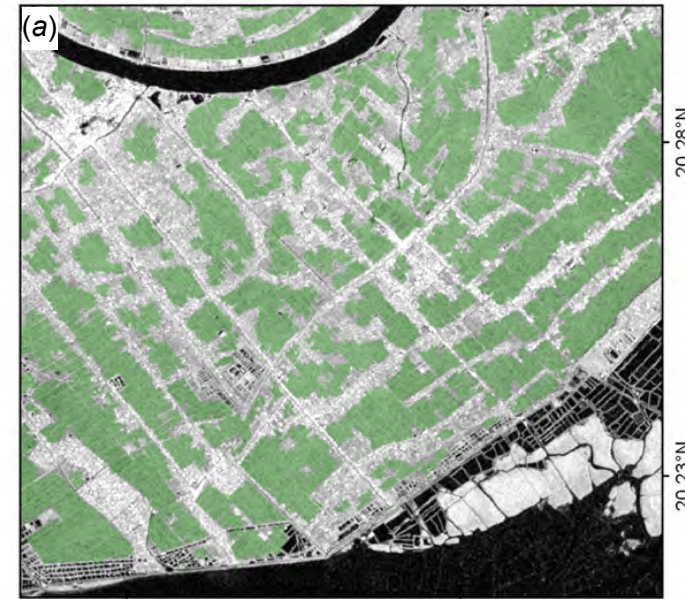

$106.45^{\circ} \mathrm{E}$
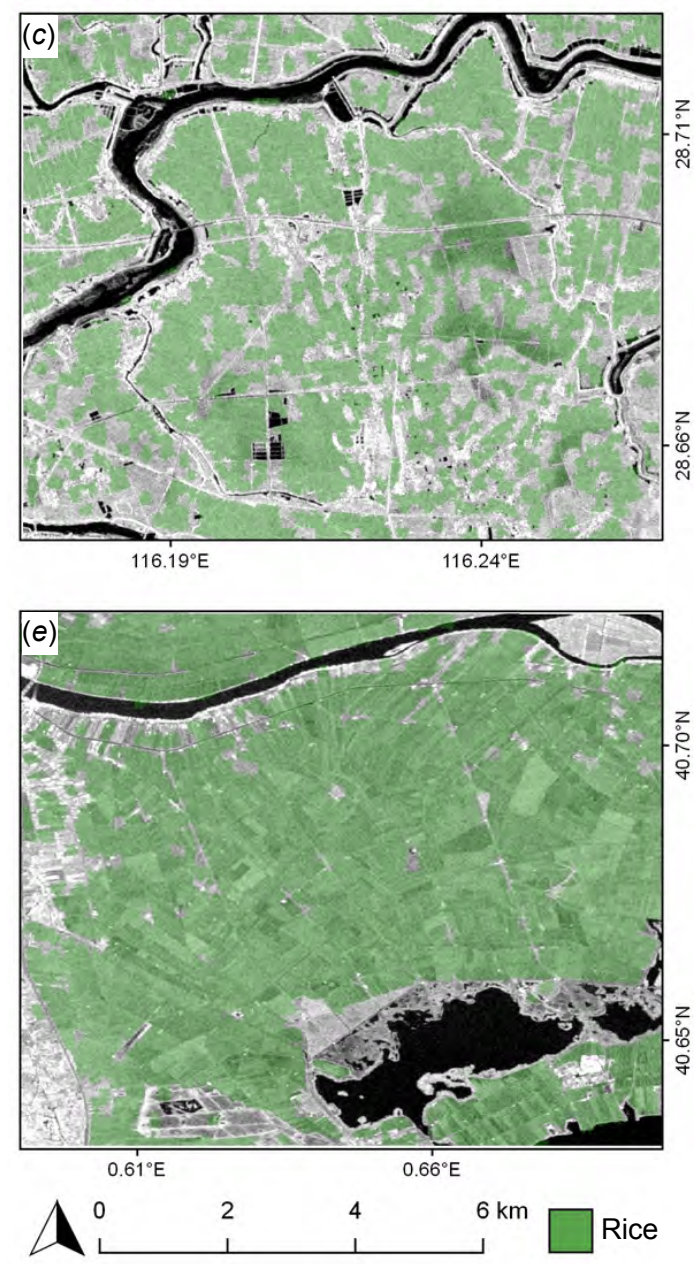

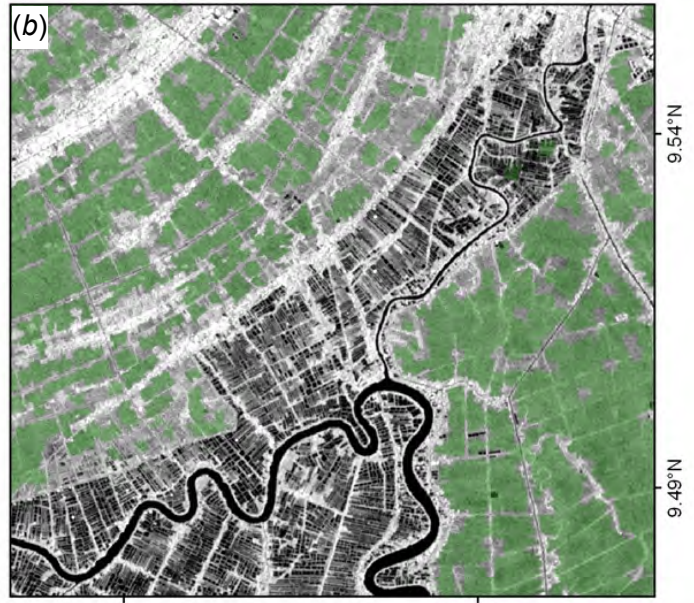

$105.93^{\circ} \mathrm{E}$

$105.98^{\circ} \mathrm{E}$

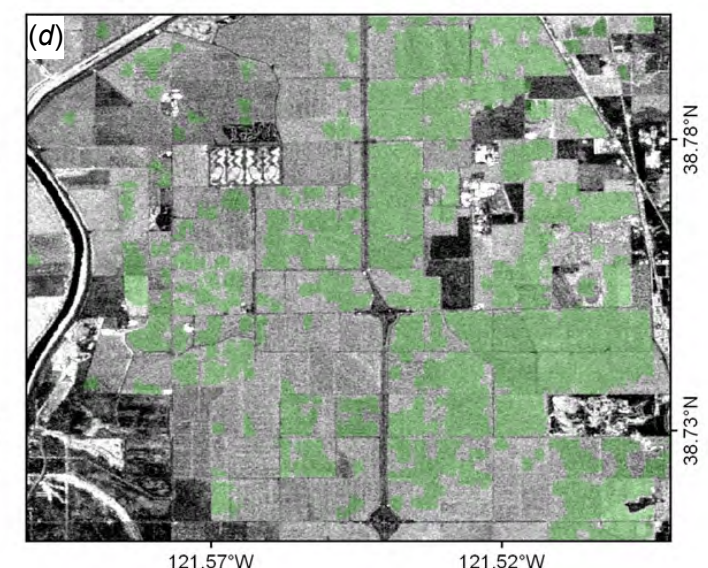

$121.57^{\circ} \mathrm{W}$

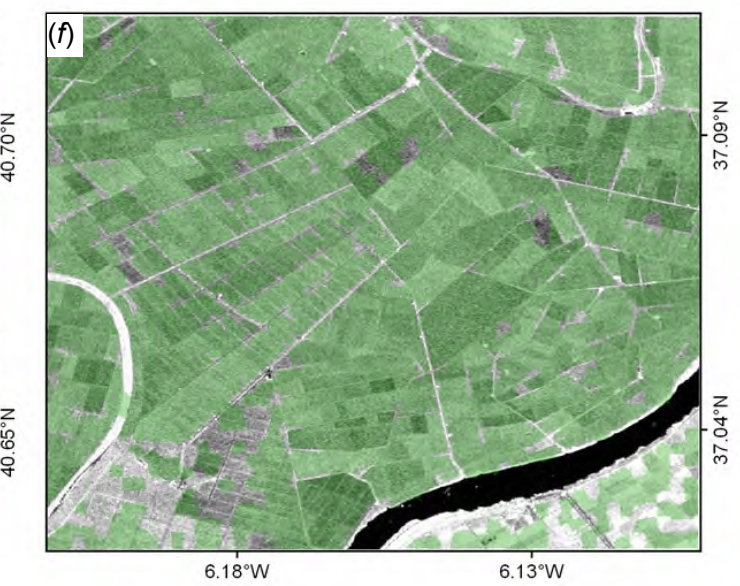

Figure 7. Paddy rice classification based on Sentinel-1A time-series from 2015 for Giao Thuy (a), Soc Trang (b), Poyang Lake (c), California (d), Ebro Delta (e) and Isla Mayor (f). Classification results are superimposed on grey scale images depicting the mean of all Sentinel-1 acquisitions at VH polarisation. 


\section{Discussion}

This paper presents a method to map rice growing areas with Sentinel-1 time-series using superpixel segmentation and phenology based decision trees. Multi-temporal segmentation helped mitigate the effects of speckle on our SAR time-series, which were classified with a phenology based decision tree. The method was able to map rice growing areas with a user accuracy greater or equal 0.82 in six different rice growing regions distributed around the globe, underlining the robustness of the approach. However, there are sources of error and points of improvement that need to be discussed.

A key aspect of this method is the spatial averaging of $\sigma^{0}$ time-series based on superpixel objects. We identified the need to perform a segmentation prior to classification for two reasons - reducing both speckle and the amount of data. Speckle can be summarized as a granular disturbance of random nature appearing in SAR images (Argenti et al. 2013). This noise causes sudden spikes or drops in pixel based timeseries and is difficult to distinguish from temporal features indicating changes in the underlying land cover such as crop growth. We calculated a spatial average for each time step to mitigate the effects of speckle on our time-series and reduce the amount of data. Each study site is covered by one million Sentinel-1 pixels, which would result in the classification of a million time-series per study site. Our segmentation procedure reduces this amount to 2500 time-series of homogeneous regions, which we assume to contain a single land cover class. This reduction in data sacrifices some spatial accuracy but helps mitigate the effects of speckle. It also reduces the amount of data to process, which is becoming an issue especially after the launch of Sentinel-1B and the increased coverage of both Sentinel-1 satellites.

Image segmentation can lead to mixed segments, when a segment not only contains our target class rice but also other land cover. This effect is similar to the mixed pixel effects regularly discussed in rice mapping efforts based on medium to low spatial resolution time-series (Xiao et al. 2006; Clauss, Yan, and Kuenzer 2016) and is a source of spatial error in our classification. This issue can be seen in the example given in figure 6 and is mostly apparent at field boundaries. When a paddy field is bordered by a narrow dyke or road, SLIC, as well as most other segmentation algorithms, fails to delineate clear boundaries along the field edge. Using a sensor with a shorter wavelength, such as X-band, could aid in the detection of smaller scatterers at the boundary of flooded fields but at the cost of less canopy penetration of the fully grown rice plants. Studies comparing different wavelengths have shown that C- and L-band are best correlated with rice growth variables (Inoue et al. 2002). While the Sentinel1 GRD datasets are delivered at $10 \mathrm{~m}$ pixel size they are acquired at a geometric resolution of $5 \mathrm{~m} \times 20 \mathrm{~m}$ (Sentinel-1 Team 2013). When multiple fields are divided by narrow objects Sentinel-1 might fail to detect them and subsequently our segmentation procedure will fail to distinguish those fields. The effects of mixed segments might be reduced by using a different data source for segmentation, such as very high resolution satellite or aerial images, or by employing a different segmentation algorithm.

The classification method we employed in this paper relies on the detection of key growing stages of rice - agronomic flooding and the heading stage. Flooding of the fields prior to transplanting/seeding or shortly after is a common rice growing technique and present in all our study sites. However, it is not the only rice cultivation practice. Rice is not dependant on the flooding of paddy fields, which is mainly performed to manage pests and weeds in order to provide ideal growing conditions for the plant. Rice grown in non-flooded environments will not be detected by our method and SAR time-series over such areas would show little distinctive features to differentiate rice from other 
cereals. A further source of misclassification is the possibility of flooding events that are not related to rice cultivation but could be caused by high precipitation events, especially during monsoon. This error source would also be present in our reference dataset as agronomic and non-agronomic flooding could not be distinguished from remote sensing reference data. Direct seeding of rice into paddy fields prior or post flooding will result in a lower backscatter signal in the time-series in contrast to transplanting of seedlings, which act as small scatterers prohibiting specular reflection of the SAR signal on the water surface. Water conservation techniques, such as alternating wetting and drying of the fields, could also lead to acquisitions without a clear flooding signal and thus the potential for underestimation. These phenomena should be carefully considered in conjunction with the density of the time-series when a phenology based decision tree classifier is applied. The requirement of agronomic flooding is fulfilled for most rice growing techniques but not all of them and is a limitation of our method regarding its transferability to other regions.

Decision trees are a robust and transparent classification method, that is easy to adapt and reproduce. However, decision trees with few nodes are not a sophisticated classification method and are therefore also a potential source of error themselves. Fixed, global thresholds may lead to overestimation of rice areas in one study site and underestimation in others. This error source is multiplied by our method classifying at the segment and not pixel level. We achieved acceptable accuracies with this empirical decision tree but expect the accuracies to be higher with the implementation of more advanced methods such as Support Vector Machines, Dynamic Time Warping or Hidden Markov Models. We therefore regard the phenology based decision tree as a baseline classification method which can be improved upon in further implementations of this rice mapping procedure.

Our method achieved the highest classification accuracies in the Giao Thuy and Ebro Delta study sites. In the Giao Thuy study site rice fields are often grouped together and separated by canals and built-up areas along streets (figure 8 - b). Builtup areas form a high contrast against rice fields and are therefore divided well during the segmentation stage of our procedure. A similar effect can be observed in the Soc Trang study site, where the canal network separates clusters of rice fields from one another (figure $8-\mathrm{h}$ ). When rice fields are bounded by land cover which contrasts well against the fields the segmentation performs well to distinguish those areas and achieve high accuracies. Conversely this also means that our method has limitations in areas with less prominent field boundaries. A contributing factor might also be, that we were able to create temporally dense time-series in Giao Thuy, Soc Trang and the Ebro Delta. For Giao Thuy we could use 23, in Soc Trang 38 and in the Ebro Delta 24 Sentinel-1 observations. In California on the other hand only 8 observations were available for time-series creation. We suspect that this largely contributes to the low accuracy we achieved in this study site. The study site is characterized by large, regular fields with clear boundaries, usually roads and pathways (figure 8 - e). Our classification method sometimes failed to accurately capture rice fields in their entirety and only classified parts of the field as rice area (figure $8-\mathrm{d}$ ). This is also a possible explanation for the low user's accuracy for the no rice class in this study area, which shows that our method had a high false negative rate in this region. Since the Ebro Delta had a much lower false negative rate, while having similar characteristics we suspect the main error source to be the temporal density of the time-series. If the Sentinel-1 acquisitions are not frequent enough they fail to measure key phenological stages in rice crop growth and subsequently our phenology based decision tree fails to accurately classify these areas. This is a limitation of our method that could be 
alleviated with the launch of Sentinel-1B and improved acquisition plans. The Isla Mayor study site exhibits false positives for the class rice in the south-east edge of the study site, south of the river. These indicate, that our decision tree fails to accurately discriminate rice from other field crops in this region. A likely explanation for this is that our classifier relies on phenology based, empirical thresholds that have been applied to all study sites. If the method is applied to regions where rice is confused with other field crops an adaption of the threshold parameters is advisable in order to better discriminate paddy rice areas. 


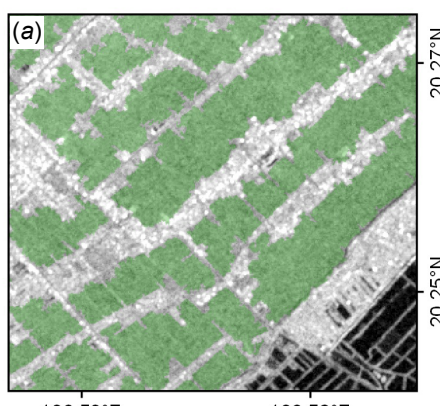

$106.50^{\circ} \mathrm{E}$

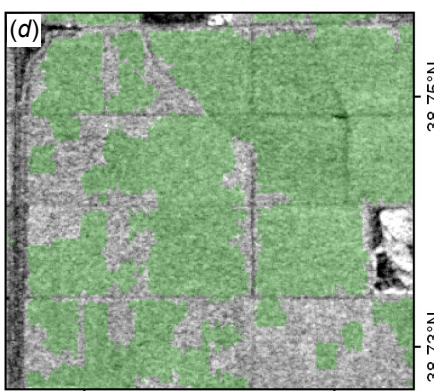

$121.54^{\circ} \mathrm{W}$

$121.52^{\circ} \mathrm{W}$

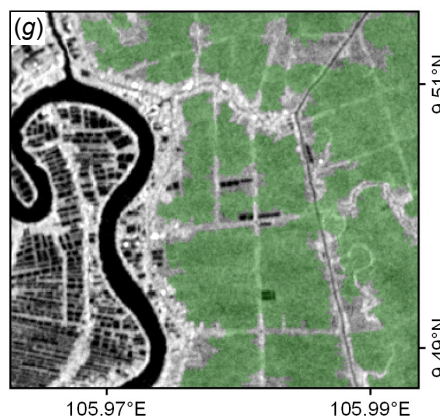

$105.97^{\circ} \mathrm{E}$

Rice

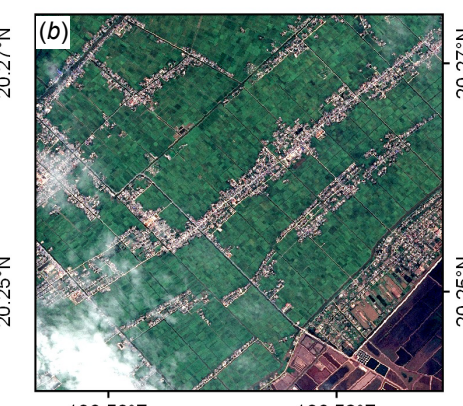

$106.52^{\circ} \mathrm{E}$

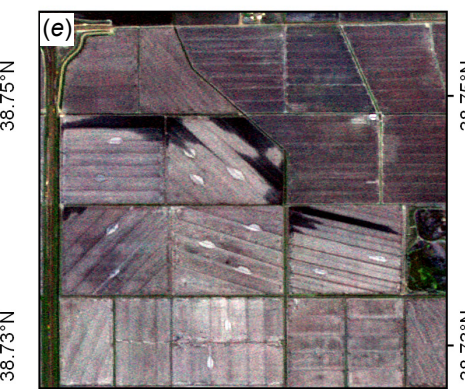

$121.52^{\circ} \mathrm{W}$

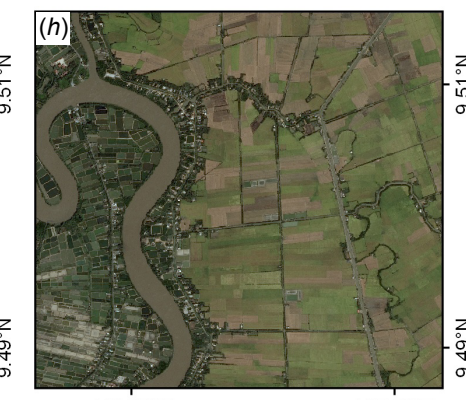

$105.97^{\circ} \mathrm{E}$

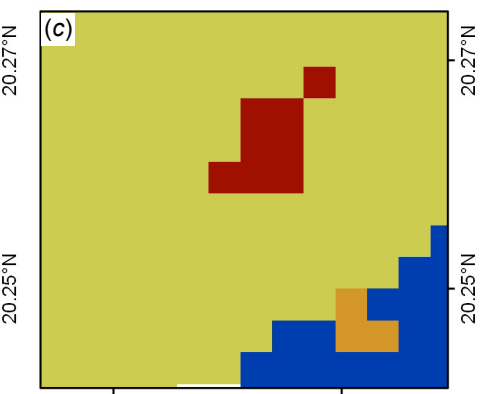

$106.50^{\circ} \mathrm{E} \quad 106.52^{\circ} \mathrm{E}$

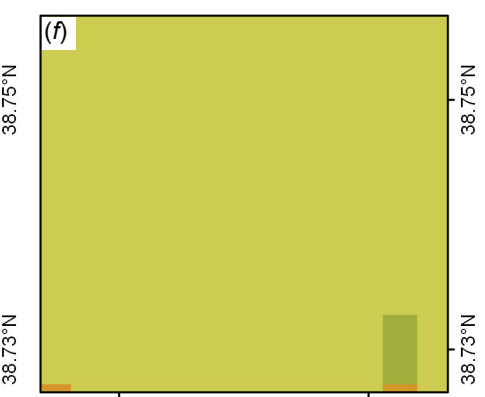

$121.54^{\circ} \mathrm{W}$

$121.52^{\circ} \mathrm{W}$

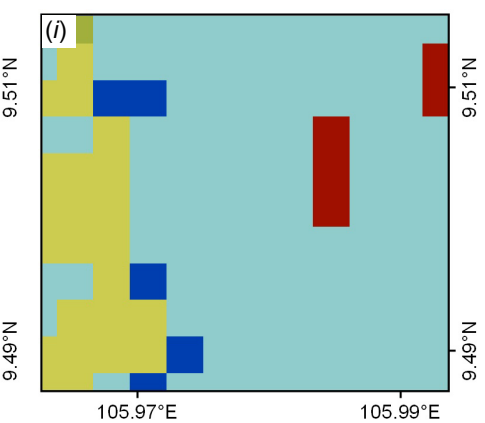

$105.97^{\circ} \mathrm{E}$

Rainfed cropland

Irrigated or post-flooding cropland

Mosaic natural vegetation cropland

Grassland

Urban areas

Water bodies
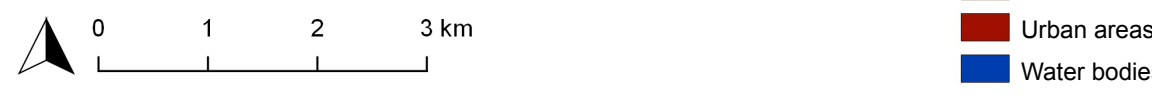

Figure 8. Comparison of our Sentinel-1A paddy rice classification (a, d, g) against VHR imagery of SPOT-6 from 30 May 2015 (b), 2 February 2015 (h) and RapidEye from 16 December 2015 (e) and ESA's global CCI

Land Cover product for 2010 (c, f, i) for subsets of the study sites Giao Thuy (a - c), California (d - f) and Soc Trang $(g-i)$ 


\section{Conclusions and Outlook}

We showed that paddy rice areas exhibiting agronomic flooding can be mapped in different regions with high resolution Sentinel-1 SAR time-series using a phenology based decision tree in combination with multi-temporal segmentation based on the SLIC (simple linear iterative clustering) algorithm. Accurate and timely mapping of rice areas at high spatial resolution has long been identified as an important task in the context of climate change, water management and food security. However, there is still a distinct lack of globally available or applicable datasets and methods for this task, despite its importance. One of the reasons for this is a lack of available remote sensing data at high spatial and temporal resolution (Kuenzer and Knauer 2013; Dong and Xiao 2016; Mosleh, Hassan, and Chowdhury 2015). The fleet of Sentinel-1 satellites and their open data archive drastically changed data availability and enables free and open access to C-band SAR time-series at high spatial and temporal resolution. We present one of the first methods that aims to map rice areas using this archive.

Incorporating the co-location architecture of the Earth Engine, meaning that our method is transported to the data archive and not vice versa, we can apply this method to different areas fast and with minimal adaption. Google Earth Engine is a cloud-based processing platform that is optimised for horizontal scaling of processes (Gorelick et al. 2017), to enable large scale processing of geospatial data by making use of Googles abundant compute resources. The co-location of remote sensing methods, data and processing infrastructure will help in the creation of high resolution remote sensing products at large scale.

Our rice mapping method uses the archive of Sentinel-1 GRD images acquired in 2015 which are delivered at a $10 \mathrm{~m}$ spatial resolution. Access to an archive of C-band SAR images at this resolution enabled us to create dense time-series necessary for the detection of rice fields in rice growing regions throughout the earth. This high spatial resolution is necessary to accurately map rice area, which becomes apparent when comparing our classification to a medium resolution, global land cover product such as one produced by ESAs climate change initiative (CCI) (Herold et al. 2011). For local to regional applications most global land cover products have neither the spatial nor thematic accuracy to characterize rice growing regions. Examples for this are given in figure 6 , where we can see a confusion of agricultural and urban areas (c) or misclassification of irrigated paddy rice fields as rainfed cropland (f). Accurate and timely information about rice growing areas is important for issues in water resource management and food security and our rice mapping method can be used to create such maps, where the spatial or thematic accuracy of existing products is lacking. Access to an archive of high spatial and temporal resolution SAR time-series is crucial for these applications.

Our method has proven robust in mapping rice areas in a variety of rice growing regions, with an average overall accuracy of 0.83 . We identified three points that could improve these results further: the temporal density of Sentinel-1 acquisitions, accuracy of the implemented segmentation algorithm and a different classification algorithm. Before applying this rice mapping method to larger areas careful consideration should be taken regarding the cost-accuracy trade-off, since changes to one of the three points likely incurs an increase in processing time. Our method builds upon previous rice area mapping approaches and helps understanding their adaption towards more accurate, timely and globally consistent rice maps based on data from the Copernicus Sentinel-1 satellite fleet. 


\section{Acknowledgement(s)}

This work was partially funded by the German Ministry of Education and Research (BMBF) through the DeltAdapt and Catch-Mekong projects. We would like to thank Dr. Xiaoping Du and Dr. Tuan Quoc Vo for their valuable input and dicussions on the remote sensing of rice areas in China and Vietnam. We would also like to thank our anonymous reviewers for their constructive comments.

\section{Disclosure statement}

The authors declare no conflict of interest.

\section{References}

Achanta, R., A. Shaji, K. Smith, A. Lucchi, P. Fua, and Sabine Susstrunk. 2012. "SLIC Superpixels Compared to State-of-the-Art Superpixel Methods." IEEE Transactions on Pattern Analysis and Machine Intelligence 34 (11): 2274-2282. http://ieeexplore.ieee.org/document/6205760/.

Alexandratos, N., and J. Bruinsma. 2012. World Agriculture Towards 2030/2050: the 2012 revision. Technical report. Rome: FAO. http://www.fao.org/docrep/016/ap106e/ap106e.pdf.

Argenti, Fabrizio, Alessandro Lapini, Tiziano Bianchi, and Luciano Alparone. 2013. "A Tutorial on Speckle Reduction in Synthetic Aperture Radar Images." IEEE Geoscience and Remote Sensing Magazine 1 (3): 6-35. http://ieeexplore.ieee.org/document/6616053/.

Aschbacher, J., A. Pongsrihadulchai, S. Karnchanasutham, C. Rodprom, D.R. R. Paudyal, and Thuy Le Toan. 1995. "Assessment of ERS-1 SAR data for rice crop mapping and monitoring." 1995 International Geoscience and Remote Sensing Symposium, IGARSS '95. Quantitative Remote Sensing for Science and Applications 3: 2183-2185. http://ieeexplore.ieee.org/lpdocs/epic03/wrapper.htm?arnumber $=524142$.

Bouman, Bas. 2009. "How much water does rice use?" Rice Today 8 (2): 28-29.

Bouvet, Alexandre, and Thuy Le Toan. 2011. "Use of ENVISAT/ASAR wide-swath data for timely rice fields mapping in the Mekong River Delta." Remote Sensing of Environment 115 (4): 1090-1101. http://linkinghub.elsevier.com/retrieve/pii/S0034425710003603.

Bouvet, Alexandre, Thuy Le Toan, and Nguyen Lam-Dao. 2009. "Monitoring of the Rice Cropping System in the Mekong Delta Using ENVISAT/ASAR Dual Polarization Data." IEEE Transactions on Geoscience and Remote Sensing 47 (2): 517-526. http://ieeexplore.ieee.org/lpdocs/epic03/wrapper.htm?arnumber=4768722.

Chakraborty, M., K. R. Manjunath, S. Panigrahy, N. Kundu, and J. S. Parihar. 2005. "Rice crop parameter retrieval using multi-temporal, multi-incidence angle Radarsat SAR data." ISPRS Journal of Photogrammetry and Remote Sensing 59 (5): 310-322.

Chakraborty, M., S. Panigrahy, and S.a. Sharma. 1997. "Discrimination of rice crop grown under different cultural practices using temporal ERS-1 synthetic aperture radar data." ISPRS Journal of Photogrammetry and Remote Sensing 52 (4): 183-191.

Choudhury, Indrani, and M. Chakraborty. 2006. "SAR signature investigation of rice crop using RADARSAT data." International Journal of Remote Sensing 27 (3): 519-534.

Clauss, Kersten, Huimin Yan, and Claudia Kuenzer. 2016. "Mapping Paddy Rice in China in 2002 2005, 2010 and 2014 with MODIS Time Series." Remote Sensing 8 (5): 434. http://dx.doi.org/10.3390/rs8050434.

Congalton, Russell G, and Kass Green. 2009. Assessing the Accuracy of Remotely Sensed Data - Principles and Practices.

De Datta, Surajit. 1981. Principles and Practices of Rice Production. New York: Wiley. 
Dobermann, Achim, and Thomas Fairhurst. 2000. Rice - Nutrient Disorders and Nutrient Management. Manila: International Rice Research Institute.

Donald, Paul F. 2004. "Biodiversity Impacts of Some Agricultural Commodity Production Systems." Conservation Biology 18 (1): 17-38. http://doi.wiley.com/10.1111/j.15231739.2004.01803.x.

Dong, Jinwei, and Xiangming Xiao. 2016. "Evolution of regional to global paddy rice mapping methods: A review." ISPRS Journal of Photogrammetry and Remote Sensing 119: 214-227. http://dx.doi.org/10.1016/j.isprsjprs.2016.05.010 http://linkinghub.elsevier.com/retrieve/pii/S0924271616300995.

Dong, Jinwei, Xiangming Xiao, Michael A. Menarguez, Geli Zhang, Yuanwei Qin, David Thau, Chandrashekhar Biradar, and Berrien Moore. 2016. "Mapping paddy rice planting area in northeastern Asia with Landsat 8 images, phenologybased algorithm and Google Earth Engine." Remote Sensing of Environment http://linkinghub.elsevier.com/retrieve/pii/S003442571630044X.

Field, Christopher B., Vicente Barros, Thomas F. Stocker, and Qin Dahe, eds. 2012. Managing the Risks of Extreme Events and Disasters to Advance Climate Change Adaptation: Special Report of the Intergovernmental Panel on Climate Change. Cambridge: Cambridge University Press. http://ebooks.cambridge.org/ref/id/CBO9781139177245.

Funk, Chris, Pete Peterson, Martin Landsfeld, Diego Pedreros, James Verdin, Shraddhanand Shukla, Gregory Husak, et al. 2015. "The climate hazards infrared precipitation with stationsa new environmental record for monitoring extremes." Scientific Data 2: 150066. http://www.nature.com/articles/sdata201566.

Gorelick, Noel, Matt Hancher, Mike Dixon, Simon Ilyushchenko, David Thau, and Rebecca Moore. 2017. "Google Earth Engine: Planetary-scale geospatial analysis for everyone." Remote Sensing of Environment (2016). http://linkinghub.elsevier.com/retrieve/pii/S0034425717302900.

Hansen, M.C., A. Egorov, P.V. Potapov, S.V. Stehman, A. Tyukavina, S.A. Turubanova, D.P. Roy, et al. 2014. "Monitoring conterminous United States (CONUS) land cover change with Web-Enabled Landsat Data (WELD)." Remote Sensing of Environment 140: 466-484. http://linkinghub.elsevier.com/retrieve/pii/S0034425713002721.

Herold, M., A. van Groenestijn, L. Kooistra, V. Kalogirou, and O. Arino. 2011. CCI Land Cover project - User Requirements Document - Version 2.2. Technical report. http://www.esalandcover-cci.org/?q=webfm_send $/ 46$.

Inoue, Y., Takashi Kurosu, H. Maeno, S. Uratsuka, T. Kozu, K. Dabrowska-Zielinska, and J. Qi. 2002. "Season-long daily measurements of multifrequency ( $\mathrm{Ka}, \mathrm{Ku}, \mathrm{X}, \mathrm{C}$, and $\mathrm{L}$ ) and full-polarization backscatter signatures over paddy rice field and their relationship with biological variables." Remote Sensing of Environment 81 (2-3): 194-204.

Jia, Mingquan, Ling Tong, Yan Chen, Yong Wang, and Yuanzhi Zhang. 2013. "Rice biomass retrieval from multitemporal ground-based scatterometer data and RADARSAT2 images using neural networks." Journal of Applied Remote Sensing 7 (1): 073509. http://remotesensing.spiedigitallibrary.org/article.aspx?doi=10.1117/1.JRS.7.073509.

Keppler, Frank, John T. G. Hamilton, Marc Braß, and Thomas Röckmann. 2006. "Methane emissions from terrestrial plants under aerobic conditions." Nature 439 (7073): 187-191. http://www.nature.com/doifinder/10.1038/nature04420.

Koppe, Wolfgang, Martin L. Gnyp, Christoph Hütt, Yinkun Yao, Yuxin Miao, Xinping Chen, and Georg Bareth. 2013. "Rice monitoring with multi-temporal and dual-polarimetric TerraSAR-X data." International Journal of Applied Earth Observation and Geoinformation 21: 568-576. http://linkinghub.elsevier.com/retrieve/pii/S0303243412001547.

Kuenzer, Claudia, Huadong Guo, Juliane Huth, Patrick Leinenkugel, Xinwu Li, and Stefan Dech. 2013. "Flood mapping and flood dynamics of the mekong delta: ENVISAT-ASARWSM based time series analyses." Remote Sensing 5 (2): 687-715.

Kuenzer, Claudia, and Kim Knauer. 2013. "Remote sensing of rice crop areas." International Journal of Remote Sensing 34 (6): 2101-2139.

Kurosu, T., M. Fujita, and K. Chiba. 1997. "The identification of rice fields using multi- 
temporal ERS-1 C band SAR data." International Journal of Remote Sensing 18 (14): 2953-2965. http://www.tandfonline.com/doi/abs/10.1080/014311697217143.

Kurosu, Takashi, Masaharu Fujita, and Kazuo Chiba. 1995. "Monitoring of rice crop growth from space using the ERS-1 C-band SAR." IEEE Transactions on Geoscience and Remote Sensing 33 (4): 1092-1096.

Le Toan, Thuy, F. Ribbes, Nicolas Floury, Masaharu Fujita, Takashi Kurosu, Li Fang Wang, Nicolas Floury, et al. 1997. "Rice crop mapping and monitoring using ERS-1 data based on experiment and modeling results." IEEE Transactions on Geoscience and Remote Sensing 35 (1): 41-56.

Li, Peng, Zhiming Feng, Luguang Jiang, Yujie Liu, and Xiangming Xiao. 2012. "Changes in rice cropping systems in the Poyang Lake Region, China during 20042010." Journal of Geographical Sciences 22 (4): 653-668. http://link.springer.com/10.1007/s11442-012-0954$\mathrm{x}$.

Li, Yan, Qifang Liao, Xia Li, Shengdong Liao, Guobin Chi, and Shaolin Peng. 2003. "Towards an operational system for regional-scale rice yield estimation using a time-series of Radarsat ScanSAR images." .

Liew, Soo Chin, Ping Chen, Suan-Pheng Kam, To-Phuc Tuong, Vo Quang Minh, and Hock Lim. 1998a. "Rice crops monitoring in the Mekong river delta using combined ERS and RADARSAT synthetic aperture radar." IGARSS '98. Sensing and Managing the Environment. 1998 IEEE International Geoscience and Remote Sensing. Symposium Proceedings. (Cat. No.98CH36174) 5 (c): 2746-2748.

Liew, Soo Chin, Suan-Pheng Kam, To-Phuc Tuong, Ping Chen, Vo Quang Minh, and Hock Lim. 1998b. "Application of multitemporal ers-2 synthetic aperture radar in delineating rice cropping systems in the mekong river delta, vietnam." IEEE Transactions on Geoscience and Remote Sensing 36 (5): 1412-1420.

Longoni, Violetta. 2010. "Rice Fields and Waterbirds in the Mediterranean Region and the Middle East." Waterbirds 33 (sp1): 83-96. http://www.bioone.org/doi/abs/10.1675/063.033.s106.

Lopez-Sanchez, Juan M., J. David Ballester-Berman, and Irena Hajnsek. 2011. "First Results of Rice Monitoring Practices in Spain by Means of Time Series of TerraSAR-X Dual-Pol Images." IEEE Journal of Selected Topics in Applied Earth Observations and Remote Sensing 4 (2): 412-422. http://ieeexplore.ieee.org/lpdocs/epic03/wrapper.htm?arnumber $=5462990$.

Lopez-Sanchez, Juan M., Fernando Vicente-Guijalba, J. David Ballester-Berman, and Shane R. Cloude. 2014. "Polarimetric Response of Rice Fields at C-Band: Analysis and Phenology Retrieval." IEEE Transactions on Geoscience and Remote Sensing 52 (5): 2977-2993. http://ieeexplore.ieee.org/lpdocs/epic03/wrapper.htm?arnumber=6562759 http://ieeexplore.ieee.org/xpls/abs_all.jsp?arnumber $=6562759$.

McNairn, H., and B. Brisco. 2004. "The application of C-band polarimetric SAR for agriculture: a review." Canadian Journal of Remote Sensing 30 (3): 525-542. http://www.tandfonline.com/doi/abs/10.5589/m03-069.

Mosleh, Mostafa K, Quazi K Hassan, and Ehsan H Chowdhury. 2015. "Application of Remote Sensors in Mapping Rice Area and Forecasting Its Production: A Review." Sensors (Basel, Switzerland) 15 (1): 769-791. http://www.ncbi.nlm.nih.gov/pubmed/25569753.

Müller, Hannes, Philippe Rufin, Patrick Griffiths, Auberto José Barros Siqueira, and Patrick Hostert. 2015. "Mining dense Landsat time series for separating cropland and pasture in a heterogeneous Brazilian savanna landscape." Remote Sensing of Environment 156: 490-499. http://linkinghub.elsevier.com/retrieve/pii/S0034425714004246.

Nelson, Andrew, Tri Setiyono, Arnel Rala, Emma Quicho, Jeny Raviz, Prosperidad Abonete, Aileen Maunahan, et al. 2014. "Towards an Operational SAR-Based Rice Monitoring System in Asia: Examples from 13 Demonstration Sites across Asia in the RIICE Project." Remote Sensing 6 (11): 10773-10812. http://www.mdpi.com/2072-4292/6/11/10773/.

Nguyen, Duy, Kersten Clauss, Senmao Cao, Vahid Naeimi, Claudia Kuenzer, and Wolfgang Wagner. 2015. "Mapping Rice Seasonality in the Mekong Delta with Multi-Year Envisat ASAR WSM Data." Remote Sensing 7 (12): 15868-15893. http://www.mdpi.com/2072- 
$4292 / 7 / 12 / 15808$.

Nguyen, Lam Dao, Hoang Phi Phung, Juliane Huth, and Cao Van Phung. 2012. "Estimation of the rice yield in the Mekong Delta using dual polarisation TerraSAR-X data." VNU Journal of Science 28: 20-28.

Panigrahy, S., M. Chakraborty, S. A. Sharma, N. Kundu, S. C. Ghose, and M. Pal. 1997. "Early estimation of rice area using temporal ERS-1 synthetic aperture radar data a case study for the Howrah and Hughly districts of West Bengal, India." International Journal of Remote Sensing 18 (8): 1827-1833.

Panigrahy, S., K. R. Manjunath, M. Chakraborty, N. Kundu, and J. S. Parihar. 1999. "Evaluation of RADARSAT Standard Beam data for identification of potato and rice crops in India." ISPRS Journal of Photogrammetry and Remote Sensing 54 (4): 254-262.

Patel, N. K., T. T. Medhavy, C. Patnaik, and a. Hussain. 1995. "Multi temporal ERS-1 SAR data for identification of rice crop." Journal of the Indian Society of Remote Sensing 23 (2): $33-39$.

Peel, M. C., B. L. Finlayson, and T. A. McMahon. 2007. "Updated world map of the KöppenGeiger climate classification." Hydrology and Earth System Sciences 11 (5): 1633-1644. http://www.hydrol-earth-syst-sci.net/11/1633/2007/.

Premalatha, M., and P. P. Nageswara Rao. 1994. "Crop acreage estimation using ERS-1 SAR data." Journal of the Indian Society of Remote Sensing 22 (3): 139-147.

Ribbes, F. 1999. "Rice field mapping and monitoring with RADARSAT data." International Journal of Remote Sensing 20 (4): 745-765. http://www.tandfonline.com/doi/abs/10.1080/014311699213172.

Richards, Erin E, Penny Masuoka, David Brett-Major, Matthew Smith, Terry A Klein, Heung Kim, Assaf Anyamba, and John Grieco. 2010. "The relationship between mosquito abundance and rice field density in the Republic of Korea." International Journal of Health Geographics 9 (1): 32. http://ij-healthgeographics.biomedcentral.com/articles/10.1186/1476072X-9-32.

Saha, Suranjana, Shrinivas Moorthi, Xingren Wu, Jiande Wang, Sudhir Nadiga, Patrick Tripp, David Behringer, et al. 2014. "The NCEP Climate Forecast System Version 2." Journal of Climate 27 (6): 2185-2208. http://journals.ametsoc.org/doi/abs/10.1175/JCLI-D-1200823.1.

Salmon, J.Meghan, Mark A. Friedl, Steve Frolking, Dominik Wisser, and Ellen M. Douglas. 2015. "Global rain-fed, irrigated, and paddy croplands: A new high resolution map derived from remote sensing, crop inventories and climate data." International Journal of Applied Earth Observation and Geoinformation 38: 321-334. http://linkinghub.elsevier.com/retrieve/pii/S0303243415000240.

Sentinel-1 Team. 2013. Sentinel-1 User Handbook - GMES-S1OPEOPG-TN-13-0001. Technical report. European Space Agency. https://sentinel.esa.int/documents/247904/685163/Sentinel-1_User_Handbook.

Shao, Yun, Xiangtao Fan, Hao Liu, Jianhua Xiao, S. Ross, B. Brisco, R. Brown, and G. Staples. 2001. "Rice monitoring and production estimation using multitemporal RADARSAT." Remote Sensing of Environment 76 (3): 310-325.

Shi, Jingjing, and Jingfeng Huang. 2015. "Monitoring Spatio-Temporal Distribution of Rice Planting Area in the Yangtze River Delta Region Using MODIS Images." Remote Sensing 7 (7): 8883-8905. http://www.mdpi.com/2072-4292/7/7/8883/.

Shimada, Masanobu, Takuya Itoh, Takeshi Motooka, Manabu Watanabe, Tomohiro Shiraishi, Rajesh Thapa, and Richard Lucas. 2014. "New global forest/non-forest maps from ALOS PALSAR data (20072010)." Remote Sensing of Environment 155: 13-31. http://linkinghub.elsevier.com/retrieve/pii/S0034425714001527.

Torbick, N, W A Salas, S Hagen, and Xiangming Xiao. 2011a. "Monitoring Rice Agriculture in the Sacramento Valley, USA With Multitemporal PALSAR and MODIS Imagery." IEEE Journal of Selected Topics in Applied Earth Observations and Remote Sensing 4 (2): 451457. http://ieeexplore.ieee.org/document/5659872/.

Torbick, Nathan, Diya Chowdhury, William Salas, and Jiaguo Qi. 2017. "Monitoring Rice Agri- 
culture across Myanmar Using Time Series Sentinel-1 Assisted by Landsat-8 and PALSAR2." Remote Sensing 9 (2): 119. http://www.mdpi.com/2072-4292/9/2/119.

Torbick, Nathan, William Salas, Xiangming Xiao, Pete Ingraham, Matthew Fearon, Chandrashekhar Biradar, Delong Zhao, Ying Liu, Peng Li, and Yonglin Zhao. 2011b. "Integrating SAR and optical imagery for regional mapping of paddy rice attributes in the Poyang Lake Watershed, China." Canadian Journal of Remote Sensing 37 (1): 17-26. http://www.tandfonline.com/doi/abs/10.5589/m11-020.

United Nations. 2015. World Population Prospects: The 2015 Revision, Key Findings and Advance Tables. Technical report. New York: United Nations.

van der Walt, Stéfan, Johannes L. Schönberger, Juan Nunez-Iglesias, François Boulogne, Joshua D. Warner, Neil Yager, Emmanuelle Gouillart, and Tony Yu. 2014. "scikit-image: image processing in Python." PeerJ 2: e453. https://peerj.com/articles/453.

Wang, Jing, Jingfeng Huang, Kangyu Zhang, Xinxing Li, Bao She, Chuanwen Wei, Jian Gao, and Xiaodong Song. 2015. "Rice Fields Mapping in Fragmented Area Using Multi-Temporal HJ-1A/B CCD Images." Remote Sensing 7 (4): 3467-3488. http://www.mdpi.com/2072$4292 / 7 / 4 / 3467 /$.

Wang, Li Fang, Jin Au Kong, Kung Hau Ding, Thuy Le Toan, F. Ribbes, and Nicolas Floury. 2005. "Electromagnetic Scattering Model for Rice Canopy Based on Monte Carlo Simulation." .

Wu, Fan, Chao Wang, Hong Zhang, Bo Zhang, and Yixian Tang. 2011. "Rice Crop Monitoring in South China With RADARSAT-2 Quad-Polarization SAR Data." IEEE Geoscience and Remote Sensing Letters 8 (2): 196-200. http://ieeexplore.ieee.org/lpdocs/epic03/wrapper.htm?arnumber=5546899.

Xiao, Xiangming, Stephen Boles, Steve Frolking, Changsheng Li, Jagadeesh Y. Babu, William Salas, and Berrien Moore. 2006. "Mapping paddy rice agriculture in South and Southeast Asia using multi-temporal MODIS images." Remote Sensing of Environment 100 (1): 95113. http://linkinghub.elsevier.com/retrieve/pii/S0034425705003433.

Xiao, Xiangming, Stephen Boles, Steve Frolking, William Salas, Berrien Moore, Changsheng $\mathrm{Li}, \mathrm{L}$. He, and R. Zhao. 2002. "Observation of flooding and rice transplanting of paddy rice fields at the site to landscape scales in China using VEGETATION sensor data." International Journal of Remote Sensing 23 (15): 3009-3022. http://www.tandfonline.com/doi/abs/10.1080/01431160110107734.

Yonezawa, Chinatsu, Masahiro Negishi, Kenta Azuma, Manabu Watanabe, Naoki Ishitsuka, Shigeo Ogawa, and Genya Saito. 2012. "Growth monitoring and classification of rice fields using multitemporal RADARSAT-2 full-polarimetric data." International Journal of Remote Sensing 33 (18): 5696-5711.

Zhang, Xiaoqian, Pengbin Zhang, Kejian Shen, and Zhiyuan Pei. 2016. "Rice identification at the early stage of the rice growth season with single fine quad Radarsat-2 data." oct, 99981J. http://proceedings.spiedigitallibrary.org/proceeding.aspx?doi=10.1117/12.2240154.

Zhu, Zhe, Curtis E. Woodcock, John Rogan, and Josef Kellndorfer. 2012. "Assessment of spectral, polarimetric, temporal, and spatial dimensions for urban and peri-urban land cover classification using Landsat and SAR data." Remote Sensing of Environment 117: 72-82. http://linkinghub.elsevier.com/retrieve/pii/S0034425711002823. 